\title{
Aplikasi Manajemen Proyek Berbasis Framework CodeIgniter dan Bootstrap di PT. Pura Barutama
}

\author{
Ramos Somya*) \\ Jurusan Teknik Informatika, Fakultas Teknologi Informasi, Universitas Kristen Satya Wacana, Salatiga \\ Jln. Diponegoro 52-60, Kota Salatiga, 50711, Indonesia \\ email: ramos.somya@uksw.edu
}

Received: 22 Januari 2018; Revised: 8 Mei 2018; Accepted: 13 Mei 2018

Copyright @2018 Politeknik Harapan Bersama Tegal. All rights reserved

\begin{abstract}
Pura Bangunan Unit of PT. Pura Barutama has responsibilities to handle new building construction and renovation of old buildings. The procedure of requesting memo to do that tasks are still processed by requesting to Pura Bangunan Unit to create a new memo. In addition, the project management process is often inaccurate and not real time. It is inefficient and ineffective because requesting memo takes 1-2 days. Sometimes, the collected requesting memo files are missing, and monitoring results are not optimal. This research will design and implement the management project application using CodeIgniter and Bootstrap framework. The results showed that the application helps and accelerates all units of PT. Pura Barutama to request a memo faster. Moreover, the memo requesting files can be stored safely and project management process can be done gradually, so that the monitoring results are accurate and real time. CodeIgniter framework made the code more simple and save. The use of Bootstrap also made this application accessible in a variety of screen sizes including on screen tablets and smartphones by providing responsive displays.
\end{abstract}

Abstrak - Unit Pura Bangunan merupakan salah satu unit di PT. Pura Barutama yang bertugas untuk menangani pembangunan gedung baru atau renovasi gedung. Proses permintaan memo untuk pembangunan gedung baru atau ronovasi gedung dari unit-unit masih diproses dengan meminta unit Pura Bangunan membuat memo untuk pekerjaan tersebut. Selain itu, dalam manajemen proses pengerjaan proyek seringkali tidak akurat dan real time. Hal tersebut tidak efisien dan efektif karena proses permintaan memo membutuhkan waktu 1-2 hari, berkas memo yang dikumpulkan kadang hilang, dan hasil monitoring tidak optimal. Pada penelitian ini dilakukan perancangan dan implementasi aplikasi manajemen proyek menggunakan framework CodeIgniter dan Bootstrap. Hasil pengujian aplikasi menunjukkan bahwa aplikasi tersebut mempermudah dan mempercepat unit-unit PT. Pura Barutama untuk melakukan permintaan memo. Berkas memo juga dapat disimpan dengan aman dan proses manajemen proyek dapat dilakukan secara bertahap sehingga hasil monitoring dapat akurat dan real time. Penggunaan framework CodeIgniter juga membuat kode program lebih ringkas dan aman. Bootstrap yang digunakan dalam aplikasi juga membuat hasil aplikasi dapat diakses di berbagai macam ukuran layar termasuk di layar tablet dan smartphone dengan tampilan yang responsif.

Kata Kunci - Manajemen Proyek, Unit Pura Bangunan, PT. Pura Barutama, Framework CodeIgniter, Bootstrap.

*) Corresponding author: Ramos Somya

Email: ramos.somya@uksw.edu

\section{PENDAHULUAN}

PT. Pura Barutama atau disebut sebagai Pura Group merupakan perusahaan yang bergerak di beberapa bidang usaha, di antaranya yaitu percetakan, pengepakan, pembuatan kertas, konversi, rekayasa, anti pemalsuan, dan teknologi kartu elektronik dan label. Pura Group memiliki 27 unit yang tersebar di lima kawasan berbeda di kota Kudus, Jawa Tengah [1].

Unit Pura Bangunan merupakan salah satu unit Pura Group yang bertugas untuk membuat bangunan baru dan renovasi bangunan. Namun, hingga saat ini permintaan untuk membangun bangunan baru atau renovasi bangunan dari berbagai unit masih diproses dengan melakukan request pembuatan memo ke Pura Bangunan kemudian mengambil berkas memo di Pura Bangunan untuk disetujui oleh bagian umum, cost control, dan pimpinan unit tersebut. Selanjutnya dikumpulkan kembali berkas memo tersebut ke Pura Bangunan. Kemudian dalam monitoring pembuatan pra Rencana Anggaran Biaya (RAB), rancangan gambar bangunan, RAB, Surat Keputusan Kerja (SPK), ketersediaan material, hingga progress pelaksanaan pembangunan oleh admin dan pimpinan unit seringkali tidak akurat dan real time. Hal tersebut tidak efisien dan efektif karena proses request pembuatan memo membutuhkan waktu sekitar 1-2 hari, memo yang telah dikumpulkan ke Pura Bangunan terkadang hilang, dan monitoring proyek tidak optimal. Unit Pura Bangunan melakukan inovasi dengan melakukan request ke unit khusus Management Information System (MIS) yang bertugas dalam penanganan masalah teknologi informasi Pura Group untuk membuat aplikasi yang dapat memudahkan berbagai unit dalam melakukan request dan monitoring.

Berdasarkan permasalahan tersebut, maka dapat diketahui rumusan masalah dalam penelitian ini adalah bagaimana merancang dan mengimplematasikan aplikasi manajemen proyek menggunakan framework CodeIgniter dan Bootstrap untuk unit Pura Bangunan, PT. Pura Barutama. Aplikasi tersebut dibangun menggunakan framework CodeIgniter sebagai back-end karena CodeIgniter merupakan salah satu framework PHP yang menggunakan MVC (Model, View, Controller) sehingga pembuatan aplikasi menjadi lebih terstruktur dan lebih aman karena tidak berhubungan langsung dengan database. Sedangkan untuk front-end menggunakan framework Bootstrap karena merupakan salah satu framework CSS yang membuat tampilan web menjadi 
responsif. Database yang digunakan adalah MySQL karena lebih sederhana dalam penggunaannya dan dapat digunakan oleh beberapa user dalam waktu bersamaan.

Mengingat begitu luasnya ruang lingkup pembuatan aplikasi manajemen proyek maka dibutuhkan batasan agar sistem yang dibangun tidak menyimpang dari permasalahan dalam sistem aplikasi manajemen proyek. Adapun batasan masalahnya yaitu proses manajemen proyek tidak menggunakan algoritma tertentu, hanya terdapat tiga user (administrator, admin unit, dan pimpinan unit), memo hanya dapat disimpan dalam bentuk PDF, dan tidak membahas keamanan jaringan. Pembuatan aplikasi manajemen proyek ini diharapkan dapat mempermudah penanganan dan monitoring proyek oleh pihak Pura Bangunan dan unit yang melakukan request sehingga progress menjadi akurat dan real time.

\section{PENELITIAN YANG TERKAIT}

Terdapat beberapa penelitian terdahulu yang digunakan sebagai acuan dalam penelitian ini. Penelitian pertama membahas tentang aplikasi manajemen proyek berbasis web menggunakan framework CodeIgniter. Aplikasi tersebut bertujuan untuk membantu perusahaan dalam menentukan konsultan TI yang menangani proyek-proyek perusahaan. Aplikasi tersebut juga membantu konsultan TI dan perusahaan dalam melihat biaya pembangunan, dokumen proyek, tanggal mulai proyek, dan tanggal selesai proyek [2].

Penelitian berikutnya adalah membahas tentang aplikasi manajemen proyek online bisnis menggunakan Microsoft Project. Aplikasi tersebut bertujuan untuk membantu memantau transaksi secara real time, mempermudah proses jual beli, dan membantu nasabah dalam memantau terhadap history transaksi [3].

Penelitian yang lain adalah pembuatan kantor digital berbasis framework dengan metode Waterfall pada Politeknik Negeri Lampung. Proses bisnis di perguruan tinggi tidak akan lepas dari berbagai permasalahan, seperti manajemen projek yang kurang rapi, atau proses manajemen lainnya, informasi yang kurang akurat dan responsi naskah atau dokumen menggunakan kertas, apabila dilakukan berulang maka dapat memicu pengeluaran dana yang tidak sedikit, pencarian dokumen hardcopy di masa yang akan datang juga sulit dilakukan karena tidak ada tempat penyimpanan secara elektronik. Maka untuk mengatasi permasalahan tersebut maka dikembangkanlah Kantor Digital berbasis framework CodeIgniter dengan metode Waterfall [4].

Penelitian mengenai pengembangan sistem aplikasi manajemen proyek berbasis Web di PT. Swadaya Graha dilakukan. Penelitian ini bertujuan untuk mengembangkan sistem aplikasi manajemen proyek yang dapat membantu perencanaan, melakukan pengawasan proyek, memberikan data laporan secara real-time, dan sebagai sarana informasi bagi para pemangku kepentingan [5]. Sedikit berbeda dengan yang dilakukan penelitian sebelumnya, pada penelitian iniberikutnya adalah pengembanga sistem informasi manajemen proyek pada PT. Marinka Tri Ananda. Aplikasi dikembangkan berbasis aplikasi dekstop menggunakan Microsoft Visual Basic 2008 dan basis data SQL Server 2008. Hasilnya, aplikasi dapat memberikan kemudahan dalam melakukan perhitungan, pemantauan, pengelolaan data-data transaksi proyek serta mengahasilkan laporan-laporan terkait [6].

Penelitian berikutnya adalah pembuatan aplikasi web manajemen proyek sistem informasi. Aplikasi ini dikembangkan dengan framework CodeIgniter. Aplikasi terbukti telah membantu manajemen proyek (pembuatan jadwal rencana hingga realisasi), pemantauan dan kontrol melalui catatan tiap detail tugas, hak akses, notifikasi dan laporan perkembangan proyek [7].

Penelitian terdahulu berikutnya membahas tentang Aplikasi Manajemen Proyek Rumah Tinggal Berbasis Web di PT. Lagagenis Insuko. Penelitian ini bertujuan untuk membuat aplikasi manajemen proyek berbasis web dengan menggunakan bahasa pemrograman PHP sebagai komponen dasar dari perancangan sistem, basis data menggunakan MySQL, untuk pemodelan dengan bahasa UML dan untuk proses desain dan pengkodean menggunakan Adobe Dreamweaver CS5 [8].

Jika dibandingkan dengan penelitian sebelumnya, aplikasi web yang dikembangkan dalam penelitian ini dibuat dengan perpaduan teknologi framework CodeIgniter dan Bootstrap. Aplikasi dirancang untuk mendukung manajemen proyek mulai dari proses pengajuan proyek, pemantauan progress proyek secara real time dan proses reporting.

\section{MANAJEMEN \& FRAMEWORK}

\section{A. Manajemen Proyek}

Manajemen merupakan proses di mana pelaksanaan dari suatu tujuan diselenggarakan dan diawasi [9]. Sedangkan proyek merupakan upaya temporer untuk menghasilkan produk, jasa, atau hasil yang tertentu/unik. Kata temporer membedakan proyek dengan pekerjaan rutin. Proyek bersifat temporer artinya waktu berlangsung dibatasi, ada awal dan ada akhir untuk pekerjaan yang dilakukan dan tim yang dibentuk [10]. Jadi, manajemen proyek merupakan suatu proses pelaksanaan pekerjaan secara bertahap dengan batas waktu tertentu yang diawasi dari awal hingga selesai untuk mencapai suatu hasil.

Manajemen Proyek juga dapat diartikan sebagai suatu ilmu dan seni untuk mengadakan perencanaan (planning), pengorganisasian (organizing), pengarahan (directing), pengoordinasian (coordinating), dan mengadakan pengawasan (controlling) terhadap orang dan barang untuk mencapai tujuan tertentu dari suatu proyek. Dengan pengertian tersebut jelaslah bahwa semua fungsi manajemen harus dipakai untuk mengelola suatu proyek, agar tujuan yang diinginkan oleh proyek tersebut dapat tercapai dengan lancar [11]. Aspek-aspek yang harus diperhatikan dalam manajemen proyek adalah: aspek keuangan, aspek angggaran biaya, aspek manajemen sumber daya manusia, aspek manajemen produksi, aspek harga, aspek efektifitas dan efisiensi waktu, aspek pemasaran, aspek mutu dan aspek waktu. Proses manajemen proyek ditunjukkan pada Gbr 1 .

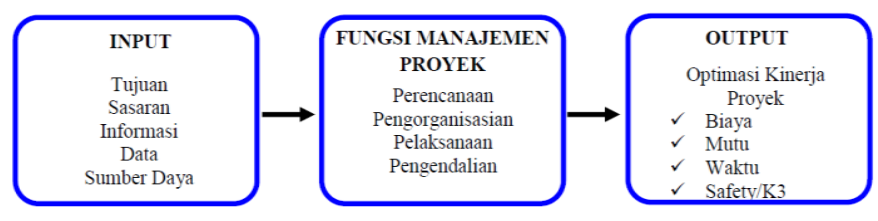

Gbr. 1 Proses dalam Manajemen Proyek 
Berdasarkan Gbr.1, proses manajemen dimulai dari kegiatan perencanaan yang berdasarkan input seperti tujuan, sasaran, informasi, data, dan sumber daya yang dilaksanakan serta dikendalikan dengan baik sehingga menghasilkan output optimasi kinerja proyek.

\section{B. Framework}

framework adalah kumpulan perintah atau fungsi dasar yang membentuk aturan-aturan tertentu dan saling berinteraksi satu sama lain sehingga dalam pembuatan aplikasi website, developer harus mengikuti aturan dari framework tersebut. Penggunaan framework bertujuan agar waktu pembuatan website menjadi lebih singkat dan pembuatan alur kode program lebih terarah [12].

\section{CodeIgniter}

CodeIgniter adalah sebuah framework PHP yang berupa kumpulan folder dan file PHP, JavaScript, CSS, TXT, dan file berbasis web lainnya dengan setting tertentu untuk menggunakannya dan menyediakan library dan helper yang dapat dimanfaatkan di dalam pemrograman PHP. CodeIgniter tergolong framework dengan ukuran kecil dan cukup mudah dikuasai [13]. CodeIgniter membutuhkan web server agar dapat dijalankan. Salah satu contoh aplikasi web server yaitu Wamp Server. CodeIgniter juga dikenal sebagai salah satu framework PHP yang menerapkan konsep MVC (Model, View, Controller). Salah satu manfaat konsep MVC adalah memisahkan kode program dengan pengelolaan database. Model berhubungan dengan database di mana di dalam model terdapat class dan fungsi untuk mengambil, menambah, mengubah, dan menghapus data suatu aplikasi. View berfungsi untuk memberikan tampilan aplikasi ke user. Sedangkan controller berfungsi sebagai jembatan penghubung antara view dan model.

\section{Bootstrap}

Bootstrap merupakan salah satu framework CSS yang sering digunakan untuk memperindah tampilan suatu website. Tujuan dari Boostrap adalah mempercepat pekerjaan. Framework ini sering digunakan oleh front-end programmer namun tidak menutup kemungkinan juga apabila digunakan oleh back-end programmer. Kelebihan dari Bootstrap ini adalah tidak hanya membuat tampilan yang statis namun dapat membuat tampilan dinamis dan beberapa animasi dengan bantuan plugin JavaScript. Selain itu juga, Bootstrap mendukung untuk membuat web responsif, yaitu tampilan akan berubah ukurannya tergantung pada resolusi layar device yang digunakan oleh user [14].

\section{METODE PENELITIAN}

Aplikasi manajemen proyek dibangun berdasarkan aturan dan prosedur yang diberikan oleh Unit Bangunan. Gbr 2 merupakan flowchart proses manajemen proyek tersebut.

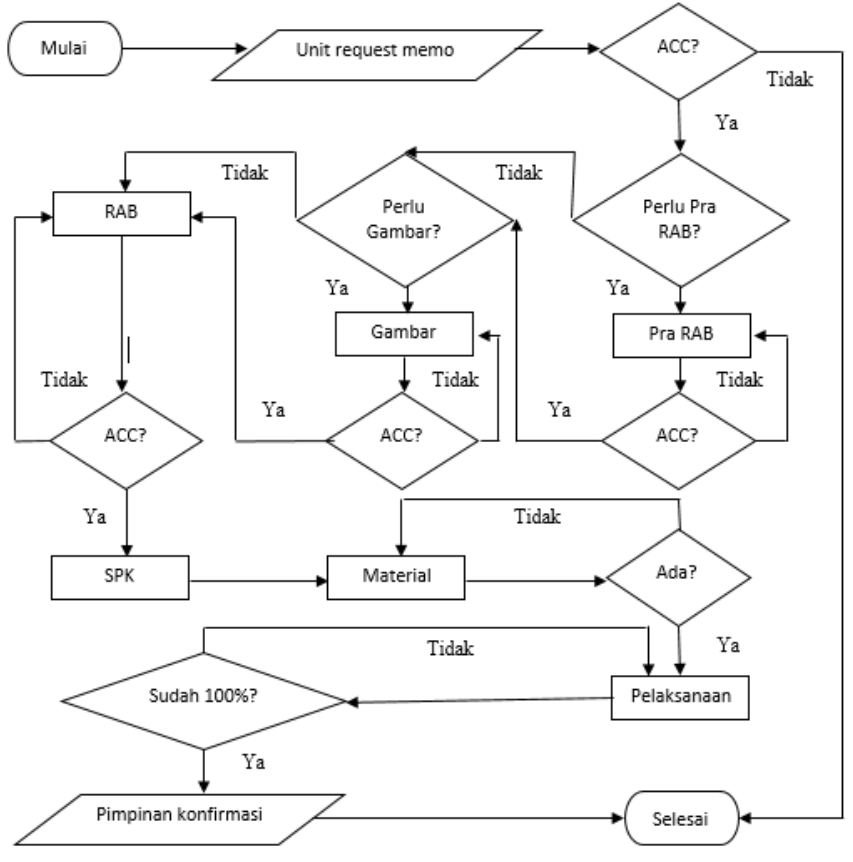

Gbr. 2 Flowchart Manajemen Proyek

Gbr 2 menunjukkan flowchart untuk aplikasi manajemen proyek. Proses tersebut adalah: (1) Unit yang akan membangun gedung atau renovasi gedung melakukan request ke unit Pura Bangunan dengan mengisi form memo online. (2) Memo tersebut akan dicek oleh administrator. Jika Pura Bangunan tidak menyetujui maka akan ditolak. Jika disetujui maka ke tahap selanjutnya yaitu membuat pra RAB (Rencana Anggaran Biaya), rancangan gambar bangunan, dan RAB oleh administrator jika dibutuhkan. Pra $\mathrm{RAB}$, rancangan gambar bangunan, dan RAB akan dicek dan disetujui oleh unit yang melakukan request. Setelah $\mathrm{RAB}$ disetujui maka unit Pura Bangunan akan menerbitkan Surat Keputusan Kerja (SPK). (3) Kemudian akan dilakukan pengecekan material. Jika material tidak tersedia maka akan proses pengerjaan ditunda hingga material tersedia. Jika material tersedia maka proses pelaksanaan pembangunan atau renovasi dimulai. (4) Selanjutnya pimpinan hanya dapat memberi konfirmasi proyek unit yang telah selesai apabila proses pengerjaan sudah selesai $100 \%$.

Tahap analisis kebutuhan user dilakukan untuk mengetahui kebutuhan user terkait dengan sistem informasi manajemen proyek yang akan dibangun. Hasil analisis user tersebut adalah: 1) Aplikasi akan digunakan oleh unit Bangunan, PT. Pura Barutama, 2) Aplikasi yang akan buat merupakan terjemahan dari proses konvensional yang sudah dilakukan selama ini, 3) Terdapat 3 aktor dalam aplikasi tersebut yaitu administrator, admin unit, dan pimpinan unit, 4) Aplikasi dibangun berbasis web sehingga dapat diakses dari tempat yang berbeda dan dengan berbagai media, 5) Perusahaan meminta untuk menggunakan framework CodeIgniter dan Bootstrap karena pada unit Management Information System (MIS) bagian pemrograman web menggunakan framework-framework tersebut.

Tahap perancangan sistem menggunakan UML (Unified Modeling Language) yang berfungsi untuk menggambarkan prosedur dan proses kerja dari aplikasi. Use case diagram adalah gambaran graphical dari beberapa atau semua aktor, use case, dan interaksi di antara komponen-komponen 
tersebut yang memperkenalkan suatu sistem yang akan dibangun [15]. Use case diagram bertujuan untuk menggambarkan fungsionalitas dari suatu sistem berdasarkan aktor, use case dan relasinya [16]. Diagram ini memiliki peranan penting sebagai suatu teknik dalam proses ekstraksi dan pendefinisian kebutuhan fungsional sistem dari sudut pandang pengguna aplikasi [17].

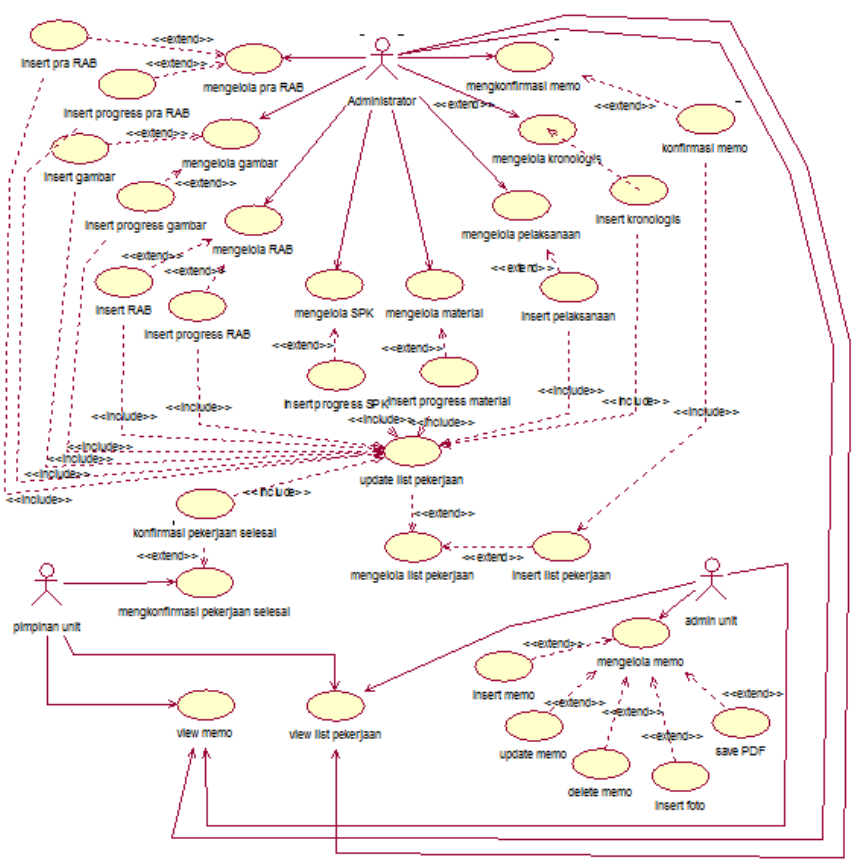

Gbr. 3 Use Case Diagram Aplikasi Manajemen Proyek

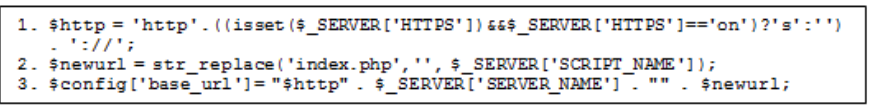

Gbr. 4 Pengaturan Base URL pada CodeIgniter

Gbr 3 merupakan use case dari aplikasi manajemen proyek. Aplikasi tersebut memiliki tiga aktor yaitu administrator, admin unit, dan pimpinan unit. Aktor admin unit memiliki hak akses untuk menambah memo baru, mengubah, menghapus, menyimpan PDF, dan menambahkan foto dari memo yang telah dibuat. Administrator memiliki hak akses paling tinggi sehingga administrator bertugas untuk memberi konfirmasi memo yang telah disetujui oleh unit Pura Bangunan. Administrator juga menambah progress pengerjaan projek yang terdiri dari pra $\mathrm{RAB}$, rancangan gambar bangunan, RAB, SPK, ketersediaan material hingga progres pengerjaan setiap harinya. Selain itu, administrator dapat melihat daftar memo dan daftar list pekerjaan dari semua unit. Pimpinan unit bertugas memberi konfirmasi untuk pekerjaan yang sudah selesai dikerjakan. Admin dan pimpinan unit juga dapat melihat daftar memo dan daftar list pekerjaan dari unit tersebut.

\section{HASIL DAN PEMBAHASAN}

Pengkodean pada framework CodeIgniter dimulai dengan membuat base URL di config.php yang terletak di dalam folder CodeIgniter. Gbr 4 menunjukkan base URL pada aplikasi manajemen proyek.
Base URL merupakan link tetap untuk mengakses resources dan link lainnya yang terdapat dalam aplikasi manajemen proyek. Base URL dalam aplikasi tersebut menggunakan base URL bersifat dinamis yang artinya bahwa ketika link tetap diubah maka base URL akan menyesuaikan dengan link tetap yang baru. Setelah membuat base URL, selanjutnya menghubungkan CodeIgniter dan Bootstrap yang ditunjukkan pada Gbr 5.

$$
\begin{aligned}
& \text { Codelgniter/ } \\
& \text { 1-- aplication/ } \\
& \text { 1-- assets/ } \\
& \text { I 1-- bootstrap/ } \\
& \text { I 1-- images/ } \\
& \text { I 1-plugins/ } \\
& \text { 1-- database/ } \\
& \text { 1-- system/ } \\
& \text { 1-- user_guide/ }
\end{aligned}
$$

Gbr. 5 Penempatan Folder Bootstrap dalam Folder CodeIgniter

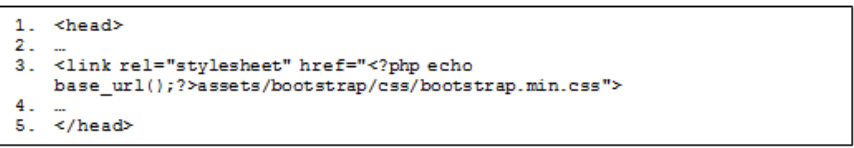

Gbr. 6 Pemanggilan Bootstrap dalam CodeIgniter

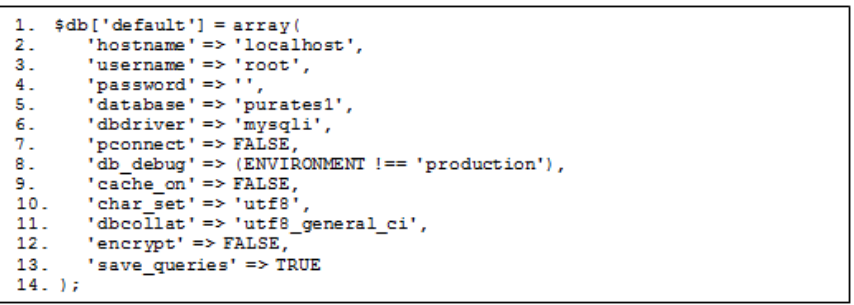

Gbr. 7 Konfigurasi Koneksi Database di CodeIgniter

1. \$route['default controller'] = 'proses' ;

3. \$route['translate_uri_dashes' $]=$ FALSE;

Gbr. 8 Konfigurasi Route CodeIgniter

Gbr 5 merupakan struktur penempatan Bootstrap dalam folder CodeIgniter. Bootstrap berada di dalam assets di mana assets tersebut dibuat untuk menampung file atau folder yang berasal dari luar folder CodeIgniter. Setelah melakukan penempatan secara benar maka dilakukan pemanggilan Bootstrap dalam pengkodean CodeIgniter yang dapat dilihat pada Gbr 6. Gbr 6 merupakan pemanggilan Boostrap di view CodeIgniter. Agar Bootstrap tersebut dapat digunakan maka perlu mengakses base URL yang telah dibuat sebelumnya. Kemudian assets merupakan tempat Bootstrap berada. Lalu pemanggilan bootstrap.min.css yang berada di dalam folder Bootstrap tersebut. Selanjutnya dilakukan konfigurasi pada CodeIgniter agar dapat terhubung dengan database yang ditunjukkan pada Gbr 7. Gbr 7 merupakan konfigurasi database yang berisi hostname, username, password, dan driver. Pada penelitian ini, database yang digunakan adalah MySQL sehingga driver yang digunakan adalah mysqli. Sedangkan untuk pengaturan route dapat dilihat pada Gbr 8 . 
Route adalah tempat untuk mengatur default controller yang dipanggil pertama kali ketika aplikasi dijalankan. Default controller pada aplikasi manajemen proyek adalah controller proses. Saat aplikasi dijalankan, controller proses akan menjalankan function index yang mengarah ke halaman login.

Aplikasi manajemen proyek PT. Pura Barutama memiliki tiga level user yaitu administrator, admin unit, dan pimpinan unit. Ketiga user tersebut memiliki hak akses yang berbeda. Penggunaan aplikasi tersebut dilakukan dengan user harus login dengan mengisi username dan password secara benar. Gbr 9 merupakan halaman daftar memo admin unit yang belum dikonfirmasi oleh administrator.

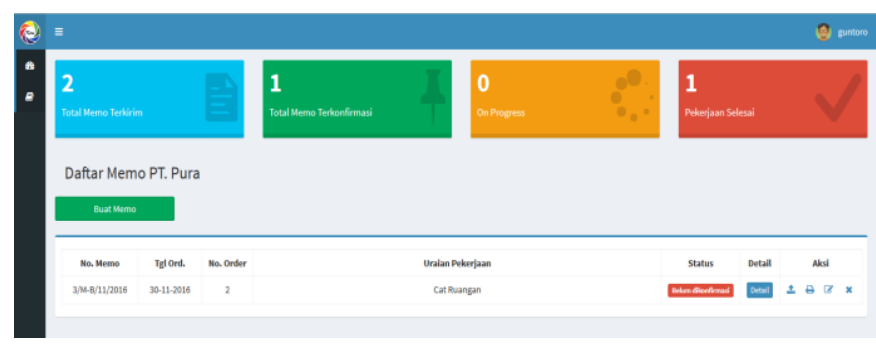

Gbr 9 Halaman Daftar Memo Admin Unit

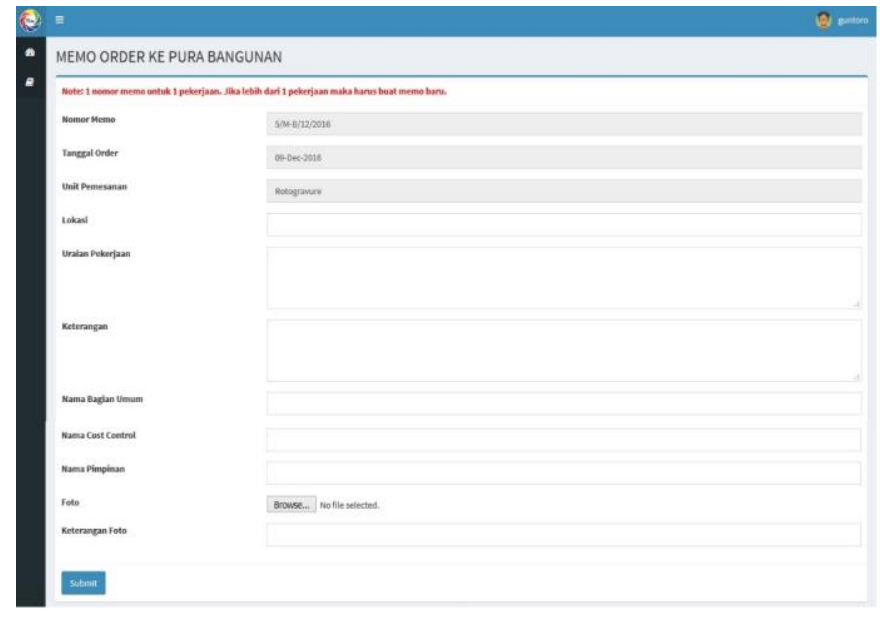

Gbr. 10 Halaman Tambah Memo oleh Admin Unit

Admin unit bertugas untuk mengelola memo. Admin unit dapat menambah memo baru, mengubah memo, menghapus memo, menyimpan memo ke PDF, dan menambah foto untuk melengkapi berkas memo. Selain itu, admin unit dapat memonitoring proyek yang sedang dikerjakan. Gbr 10 merupakan halaman untuk menambah memo baru.

Setiap pembuatan memo akan mendapatkan nomor memo dimana memo tersebut hanya berlaku untuk satu pekerjaan saja. Jika terdapat lebih dari satu pekerjaan maka admin unit harus membuat memo baru lagi. Setelah berhasil menambah memo baru, admin unit dapat menyimpan memo tersebut dalam bentuk PDF seperti terlihat pada Gbr 11.

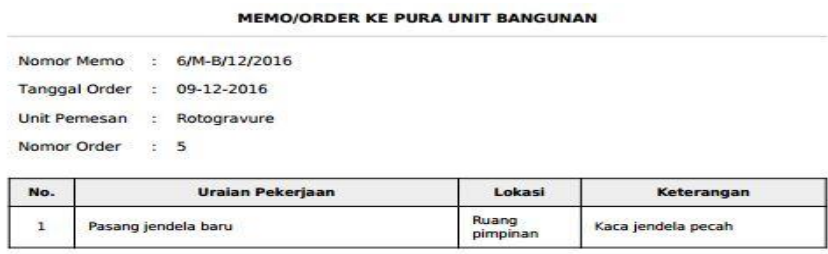

Kudus. 09-12-2016

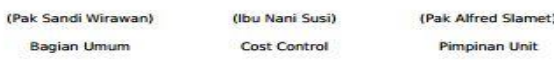

Gbr. 11 Tampilan Memo dalam PDF

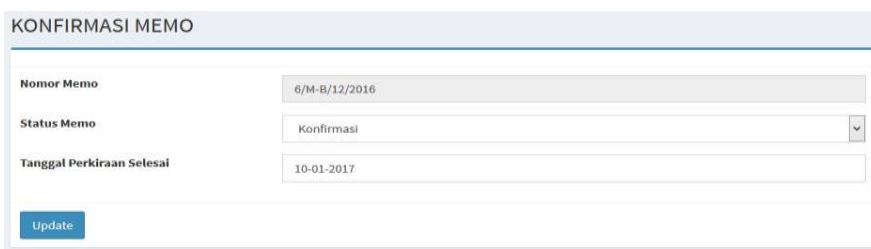

Gbr. 12 Konfirmasi Memo oleh Administrator

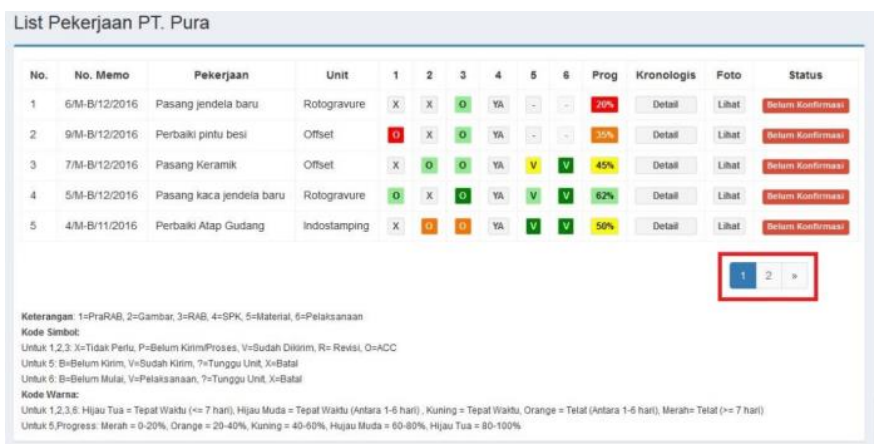

Gbr.13 Halaman Daftar List Pekerjaan

Administrator bertugas untuk mengkonfirmasi memo dari unit-unit PT. Pura Barutama dan memanajemen proyekproyek yang sedang dikerjakan. Dalam memanajemen proyek, administrator harus mengisi progress pengerjaan dari pra $\mathrm{RAB}$, rancangan gambar, RAB, SPK, ketersediaan material, pelaksanaan, dan kronologis setiap harinya. Proses konfirmasi memo dapat dilihat pada Gbr 12. Gbr 12 merupakan form konfirmasi memo dengan memilih status memo "Konfirmasi" dan mengisi tanggal perkiraan proyek selesai dikerjakan. Setelah melakukan konfirmasi, administrator dapat memulai menambahkan progres proyek sesuai dengan tahap pengerjaan yang sedang dilakukan. Daftar list pekerjaan ditunjukkan pada Gbr 13.

Gbr. 13 merupakan halaman daftar list pekerjaan administrator. Administrator wajib untuk menambah progres dari pra RAB, gambar, RAB, SPK, material, pelaksanaan, dan kronologis keseluruhan pekerjaan setiap harinya hingga proyek $100 \%$ telah selesai. Unit Pura Bangunan memiliki persyaratan warna sesuai dengan ketentuan yang berlaku pada unit Pura Bangunan dalam melakukan manajemen proyek. Ketentuan pewarnaan untuk pra RAB, gambar, RAB, dan pelaksanaan yaitu hijau tua artinya lebih awal $(<=7$ hari), hijau muda artinya lebih awal (antara 1-6 hari), kuning artinya 
tepat waktu, oranye artinya telat (antara 1 -6 hari), dan merah artinya telat $(>=7$ hari). Sedangkan pewarnaan untuk material dan progres keseluruhan pengerjaan yaitu merah artinya progres antara $0-20 \%$, oranye artinya progres antara $21-40 \%$, kuning artinya progres antara 41-60\%, hijau muda artinya progres antara $61-80 \%$, dan hijau tua artinya progres antara 81-100\%. Apabila progres keseluruhan selesai 100\% maka pimpinan unit dapat memberi konfirmasi bahwa pekerjaan telah selesai agar dinyatakan selesai secara sah. Proses dalam aplikasi ini sesuai dengan kriteria/aspek dalam konsep manajemen proyek, yaitu aspek waktu dan aspek efektifitas dan efiesiensi. Aspek waktu di sini ditunjukkan dengan kemampuan sistem manajemen proyek ini untuk menampilkan perkembangan dari setiap proyek yang akan, sedang dan telah selesai dikerjakan. Pengguna juga dapat melihat rincian setiap proyek yang dikerjakan. Aspek efektifitas dan efisiensi didukung oleh sistem ini dengan adanya penyederhanaan proses manajemen proyek sebelumnya ke dalam sistem web.

Tampilan aplikasi manajemen proyek dibangun menggunakan framework Bootstrap agar tampilan dapat responsif sesuai dengan resolusi layar. Contoh tampilan responsif dapat dilihat pada Gbr 14. Tampilan tersebut merupakan contoh tampilan halaman daftar memo pada setengah layar menggunakan web browser Mozilla Firefox. Penggunaan Bootstrap bertujuan agar tampilan tetap rapi dan indah mengikuti ukuran layar. Pembuatan tampilan responsif pada aplikasi ini secara umum dapat dilihat pada Gambar 14 Bootstrap di sini digunakan juga untuk mendukung fungsifungsi dalam manajemen proyek, yaitu fungsi perencanaan, pengorganisasian, pelaksanaan dan pengendalian yang disajikan dalam tampilan yang informatif dalam halaman web

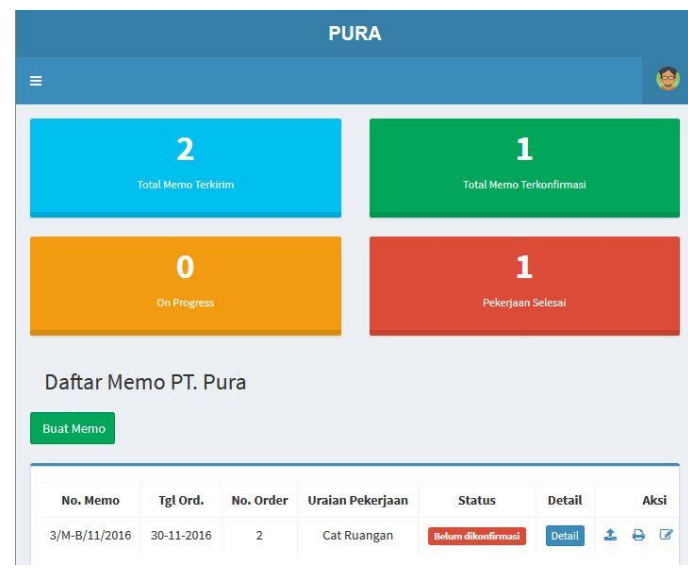

Gbr.14 Tampilan Responsif

Jika dibandingkan dengan Sistem Informasi yang dikembangkan pada tujuh penelitian terdahulu, maka Sistem Informasi pada penelitian ini lebih baik dari sisi responsibilitas layar. Berdasarkan pengujian, aplikasi dapat diakses dari layar browser komputer, laptop, tablet dan smartphone dengan lebih baik karena sudah didukung dengan teknologi responsive web. Tampilan web tidak akan berantakan atau terpotong dengan adanya fitur responsive web ini.

Selain itu, dari sisi pengkodean aplikasi juga lebih baik karena penggunaan framework CodeIgniter memungkinkan web developer untuk menggunakan fitur Active Record, yaitu fungsi akses ke basis data yang sudah disediakan oleh CodeIgniter. Fungsi ini membuat web developer tidak perlu menuliskan query SQL di dalam kode program.

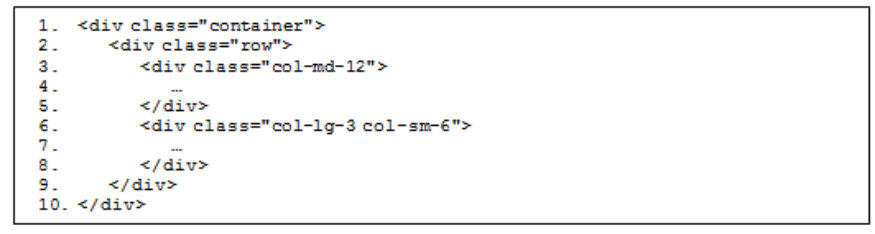

Gbr.15 Pembuatan Tampilan Responsif dengan Bootstrap

Bootstrap memiliki sistem grid yang membagi layar menjadi 12 kolom. Sistem grid pada Bootstrap dibagi menjadi 4 yaitu large (col-lg-*) digunakan untuk mengatur grid pada monitor komputer berukuran besar, medium (colmd-*) digunakan untuk mengatur grid pada monitor komputer berukuran sedang, small (col-sm-*) digunakan untuk mengatur grid pada monitor komputer berukuran tablet, dan extra small (col-xs-*) digunakan untuk mengatur grid pada monitor komputer berukuran layar telepon selular. Gbr 14 merupakan salah satu script Bootstrap untuk membuat tampilan responsif. Baris 3 berfungsi untuk membuat satu layar penuh. Sedangkan baris 6 terdapat class col-lg-3 dan col-sm-6. Col-lg-3 digunakan membagi satu layar penuh menjadi 4 bagian. Col-sm-6 digunakan untuk membagi satu layar penuh menjadi 2 bagian.

Pengujian aplikasi dilakukan dengan menguji fungsifungsi dari aplikasi yang telah dibuat untuk mencari kesalahan pada aplikasi tersebut. Pengujian dilakukan untuk mengetahui apakah aplikasi yang dibuat sudah berjalan dengan baik dan sesuai dengan kebutuhn user. Pengujian aplikasi ini menggunakan dua teknik pengujian yaitu pengujian alpha dan pengujuan beta.

Pengujian alpha menggunakan metode Blackbox yaitu pengujian fungsi-fungsi aplikasi secara langsung tanpa memperhatikan alur eksekusi program [18]. Pengujian ini dilakukan dengan memperhatikan apakah fungsi telah berjalan sesuai rancangan dan yang diharapkan. Pengujian ini dilakukan pada fungsi-fungsi di aplikasi yaitu login, menampilkan daftar memo setiap unit, menambah memo baru, mengubah data memo, mengapus data memo, mengunduh file memo dalam format PDF, menambah foto memo, memonitor list pekerjaan, konfirmasi memo, Memanajemen proyek dalam daftar list pekerjaan dan mengkonfirmasi pekerjaan telah selesai. Beberapa hasil pengujian disajikan pada TABEL 1 . 
TABEL I

PENGUJIAN BLACKBOX

\begin{tabular}{|c|c|c|c|c|}
\hline Fungsi yang diuji & Kondisi & Output yang diharapkan & $\begin{array}{c}\text { Output yang dihasilkan } \\
\text { sistem }\end{array}$ & Status pengujian \\
\hline $\begin{array}{l}\text { Menampilkan daftar } \\
\text { memo setiap unit }\end{array}$ & $\begin{array}{l}\text { Membuka halaman daftar } \\
\text { memo setiap unit }\end{array}$ & Sukses tampilkan data & Sukses tampilkan data & Valid \\
\hline Menambah memo baru & Mengisi form memo & $\begin{array}{l}\text { Sukses tambah data } \\
\text { memo }\end{array}$ & $\begin{array}{l}\text { Sukses tambah data } \\
\text { memo }\end{array}$ & Valid \\
\hline $\begin{array}{l}\text { Memanajemen proyek } \\
\text { dalam daftar list } \\
\text { pekerjaan }\end{array}$ & $\begin{array}{l}\text { Membuka halaman list } \\
\text { pekerjaan dan mengisi } \\
\text { progress pengerjaan pra } \\
\text { RAB, rancangan gambar, } \\
\text { RAB, SPK, material, } \\
\text { pelaksanaan, dan } \\
\text { kronologis }\end{array}$ & $\begin{array}{l}\text { Sukses manajemen } \\
\text { proyek }\end{array}$ & $\begin{array}{l}\text { Sukses manajemen } \\
\text { proyek }\end{array}$ & Valid \\
\hline $\begin{array}{l}\text { Konfirmasi pekerjaan } \\
\text { selesai }\end{array}$ & $\begin{array}{l}\text { Memilih proyek dengan } \\
\text { progress } 100 \% \text { selesai } \\
\text { Memilih proyek dengan } \\
\text { progress belum } 100 \% \\
\text { selesai }\end{array}$ & $\begin{array}{l}\text { Sukses konfirmasi } \\
\text { Gagal konfirmasi }\end{array}$ & $\begin{array}{l}\text { Sukses konfirmasi } \\
\text { Gagal konfirmasi }\end{array}$ & Valid \\
\hline
\end{tabular}

Pengujian beta dilakukan dengan melakukan presentasi bersama empat programmer di bagian Managemen Information System (MIS) dan dua pegawai unit PT. Pura Barutama. Berdasarkan hasil presentasi tersebut didapatkan bahwa aplikasi manajemen proyek PT. Pura Barutama dapat mempermudah dan mempercepat unit-unit untuk melakukan request memo pembangunan gedung baru atau renovasi gedung. Berkas memo juga dapat disimpan dengan aman.

Selain itu, administrator dapat melakukan proses manajemen secara bertahap dan unit yang melakukan request dapat monitoring proyek yang terdiri dari pra RAB, rancangan gambar bangunan, RAB, SPK, ketersedian material, pelaksanaan dan kronologis pengerjaan setiap harinya secara akurat dan real time.

\section{KESIMPULAN}

Berdasarkan penelitian dan hasil pengujian yang telah dilakukan, maka dapat disimpulkan bahwa aplikasi manajemen proyek dapat dibuat menggunakan framework CodeIgniter dan Bootstrap. Pengunaan CodeIgniter dengan konsep MVC bermanfaat untuk penulisan kode program lebih terstruktur dan lebih aman karena user tidak berhubungan secara langsung dengan database. Selain itu, CodeIgniter menyediakan fungsi CRUD (Create, Read, Update, Delete) dan library yang mempermudah dalam pembuatan aplikasi tersebut. Sedangkan penggunaan Bootstrap bermanfaat untuk membuat tampilan aplikasi menjadi responsif yang dapat menyesuaikan dengan berbagai resolusi layar device.

Berdasarkan hasil pengujian, aplikasi manajamen proyek dapat mempermudah dan mempercepat unit-unit untuk melakukan request pembuatan memo pembangunan gedung baru atau renovasi gedung. Berkas memo juga dapat disimpan dengan aman. Selain itu, administrator dapat melakukan proses manajemen secara bertahap dan unit yang melakukan request dapat memantau proyek yang terdiri dari pra $\mathrm{RAB}$, rancangan gambar bangunan, $\mathrm{RAB}$, SPK, ketersedian material, pelaksanaan dan kronologis pengerjaan setiap harinya secara akurat dan real time. Hal ini juga telah sesuai dengan konsep manajemen proyek yang ada.

\section{UCAPAN TERIMA KASIH}

Penulis mengucapkan terima kasih kepada pihak PT. Pura Barutama, Kudus terutama bagian Management Information System (MIS) atas bantuannya selama proses penelitian. Penelitian di PT. Pura Barutama ini berlangsung pada bulan Juli hingga Oktober 2016.

\section{DAFTAR PUSTAKA}

[1] Anonymous. (2017) Pura Group [online]. Available: https://www.puragroup.com/en/home/. [Accessed: 07-Sep-2017].

[2] P. Dewi, "Rancang Bangun Sistem Informasi Kolaboratif Berbasis Web untuk Manajemen Proyek Teknologi Informasi," Jurnal Buana Informatika, vol. 6, no. 3, pp. 195-202, 2015.

[3] Noerlina, "Perencanaan Manajemen Proyek Sistem Informasi dan Teknologi Informasi Online Bisnis," Jurnal Piranti Warta, vol. 11, no. 3, pp. 440-450, 2013.

[4] S. J. Jaya, and D. Sahlinal, "Perancangan Kantor Digital Berbasis Framework dengan Metode Waterfall pada Politeknik Negeri Lampung," Jurnal Informatika : Jurnal Pengembangan IT (JPIT), vol. 2, no. 2, pp. 14-17, 2017.

[5] A. R. Dhuha, F. Pradana, and B. Priyambadha, "Pengembangan Sistem Aplikasi Manajemen Proyek Berbasis Web (Studi Kasus: PT. Swadaya Graha)," Jurnal Pengembangan Teknologi Informasi dan Ilmu Komputer, vol. 1, no. 11, pp. 1367-1375, 2017.

[6] Y. Artiningsih, S. Sartika, R. Teguh, and D. Oktaviany, "Sistem Informasi Manajemen Proyek pada PT. Marinka Tri Ananda," Skripsi, STMIK GI MDP, 2014.

[7] Sheren, "Aplikasi Manajemen Proyek Sistem Informasi," Jurnal Ilmiah Mahasiswa Universitas Surabaya, vol. 2, no. 2, pp. 1-9, 2013.

[8] E. Witasari, "Aplikasi Manajemen Proyek Rumah Tinggal Berbasis Web (Studi Kasus PT. Lagagenis Insuko)," Skripsi, Universitas Esa Unggul, 2014.

[9] H. Ismaniar, Manajemen Unit Kerja. Deepublish, 2015

[10] R. Tantra, Manajemen Proyek Sistem Informasi. Andi, 2012.

[11] B. Pujiono. (2017) Konsep Manajemen Proyek [online]. Available : http://repository.ut.ac.id/3983/1/ADPU4338-M1.pdf. [Accessed: 07Dec-2017].

[12] Wardana, Menjadi Master PHP dengan Framework CodeIgniter. Elex Media Komputindo, 2010.

[13] A. Sofwan, (2016) Belajar PHP dengan Framework CodeIgniter [online]. Available : http://ilmukomputer.org/2010/05/02/belajar-phpdengan-framework-code-igniter. [Accessed: 07-Dec-2017].

[14] Hasin, and M. Khoirul, Seri-1 Bootstrap: Persiapkan Dirimu!!! Erlangga, 2015.

[15] Christine, (2016) Mengenal Use Case Diagram [online]. Available : http://www.academia.edu/5295802/Mengenal_Use_Case_Diagram. [Accessed: 07-Dec-2017]. 
[16] H. Eichelberger, "Automatic Layout of UML Use Case Diagrams," SoftVis '08 Proceedings of the 4th ACM Symposium on Software Visualization, Munich, Germany, pp. 105-114, 2008.

[17] B. Bonilla-Morales, S. Crespo, and C. Clinie, "Reuse of Use Cases Diagrams: An Approach based on Ontologies and Semantic Web
Technologies," IJCSI International Journal of Computer Science, vol. 9, no. 2, pp. 24-29, 2012.

[18] M. S. Mustaqbal, R. F. Firdaus, and H. Rahmadi, "Pengujian Aplikasi Menggunakan Black Box Tesing Boundary Value Analysis," Jurnal Ilmiah Teknologi Informasi Terapan (JITTER), vol. 1, no. 3, pp. 31 36, 2015. 